\title{
Anti-Hypertensive Effect of Sacubitril/Valsartan: A Meta- Analysis of Randomized Controlled Trials
}

\author{
Renato De Vecchis ${ }^{\mathrm{a}, \mathrm{b}}$, Silvia Soreca ${ }^{\mathrm{a}}$, Carmelina Ariano ${ }^{\mathrm{a}}$
}

\begin{abstract}
Background: For elderly patients suffering from arterial hypertension, a complete assessment of the efficacy and safety of sacubitril/ valsartan used as an anti-hypertensive agent is not available yet. Therefore, we decided to perform a meta-analysis of randomized controlled trials (RCTs) to explore some endpoints concerning antihypertensive efficacy as well as safety of sacubitril/valsartan in elderly hypertensive patients.
\end{abstract}

Methods: PubMed and Scopus have been extensively investigated with the help of some key words until June 15, 2018. The meta-analysis incorporated exclusively RCTs in which the anti-hypertensive efficacy and safety of sacubitril/valsartan were compared with those of a reference drug (comparator) that could be an angiotensin-converting enzyme inhibitor (ACEi), an angiotensin receptor blocker (ARB), a calcium channel blocker (CCB) or a beta-blocker. Continuous ambulatory blood pressure monitoring was required as an inclusion criterion in the studies to be included in the meta-analysis. The mean reductions in systolic blood pressure and diastolic blood pressure in the sitting position (msSBP and msDBP, respectively), as well as the mean reductions in ambulatory systolic blood pressure (maSBP) and ambulatory diastolic blood pressure (maDBP), were assumed as efficacy endpoints. Adverse events (AEs) were taken as safety outcomes.

Results: Five RCTs were included with a total of 1,513 patients for analysis. In all studies, the comparator drug was an ARB (valsartan in two cases and olmesartan in the remaining three cases). Compared with ARBs, after 12 weeks there was a significant reduction in msSBP (weight mean difference $(\mathrm{WMD})=-5.41 \mathrm{~mm} \mathrm{Hg}, 95 \%$ confidence interval $(\mathrm{CI})$ : -7.0 to $-3.8 ; \mathrm{P}<0.01)$, $\mathrm{msDBP}(\mathrm{WMD}=-1.22 \mathrm{~mm} \mathrm{Hg}$, $95 \%$ CI $:-2.15$ to $-0.3 ; \mathrm{P}<0.01$ ), $\operatorname{maSBP}(\mathrm{WMD}=-4.58 \mathrm{~mm} \mathrm{Hg}$, 95\% CI: -5.62 to $-3.54 ; \mathrm{P}<0.01)$ and $\mathrm{maDBP}(\mathrm{WMD}=-2.17 \mathrm{~mm} \mathrm{Hg}$, $95 \%$ CI: -2.78 to $-1.56 ; \mathrm{P}<0.01)$ in elderly hypertensive patients at 12 weeks.

Conclusions: Sacubitril/valsartan may reduce arterial pressure more

Manuscript submitted December 5, 2018, accepted January 15, 2019

aPreventive Cardiology and Rehabilitation Unit, DSB 29 "S. Gennaro dei Poveri Hospital", via S.Gennaro dei Poveri 25, 80136 Napoli, Italy

${ }^{b}$ Corresponding Author: Renato De Vecchis, Preventive Cardiology and Rehabilitation Unit, DSB 29 "S. Gennaro dei Poveri Hospital", via S.Gennaro dei Poveri 25, 80136 Napoli, Italy. Email: devecchis.erre@virgilio.it

doi: https://doi.org/10.14740/cr813 efficaciously than ARBs in elderly hypertensive patients. These results have to be confirmed by further RCTs with a good methodological quality, possibly with a greater sample size.

Keywords: Sacubitril/Valsartan; Hypertension; Therapy

\section{Introduction}

Various studies have revealed the potential of sacubitril/valsartan as an anti-hypertensive agent [1-5]. However, some perplexities and fears have made the path toward the validation of the drug for the indication of the arterial hypertension uneven and difficult $[6,7]$. This places the sacubitril/valsartan in antithesis with the route followed by other drugs, such as enalapril, for which the indication for arterial hypertension and for heart failure occurred in a rapid sequence one after the other $[8,9]$. Undoubtedly, the existence of a gap of knowledge about the effect of long-term inhibition of cerebral neprilysin [7] by sacubitril has played a non-negligible role in the case of the current difficulties to recognize sacubitril/valsartan as an anti-hypertensive agent. In fact, the fear that the aforementioned enzymatic inhibition could favor noxious reactions of neuronal toxicity from cerebral accumulation of beta-amyloid has entailed the fact that hypertension, a condition for which any drug therapy must be conducted for decades, has been excluded from the therapeutic indications of sacubitril/valsartan [5].

In other words, the risk of a "mild cognitive impairment" caused by chronic inhibition of cerebral neprilysin was considered as an acceptable risk in the presence of heart failure in the New York Heart Association (NYHA) classes II-III, which directly threatens the short-term survival of patient. Instead, the same risk appeared as an unfavorable factor sufficient to discourage the approval of sacubitril/valsartan as a drug for the treatment of hypertension. This last chronic morbid condition does not threaten the patient's survival in the short term; moreover, there are already numerous drugs that have been shown to be efficacious and safe for the treatment of hypertension.

However, recently, based on data from the studies on sacubitril/valsartan in heart failure [10-12], it has become evident that at the recommended therapeutic doses, which are 100 to $400 \mathrm{mg}$ per day of sacubitril/valsartan, the clinical manifestations of neuronal toxicity have no or negligible relevance. 
Therefore, several randomized controlled trials (RCTs), aimed at evaluating the efficacy and safety of sacubitril/valsartan as an anti-hypertensive agent, and mostly focused on its use for isolated systolic hypertension in the elderly, have been authorized by the ethics committees in recent years [13-17].

\section{Purpose of the study}

The present meta-analysis addressed the study of the efficacy and safety of sacubitril/valsartan for hypertension, deriving the necessary information from RCTs collected from the literature.

\section{Methods}

We performed our meta-analysis and wrote the article by conforming to requirements illustrated in the Preferred Reporting Items for Systematic Reviews and Meta-Analyses (PRISMA) statement [18].

\section{Studies' requirements and data extraction}

All data were obtained by actively searching of PubMed and Scopus electronic archives up to June 15, 2018. Studies had to be RCTs and were incorporated in the meta-analysis if they met the following criteria: 1) Studies had to be aimed to investigate efficacy and safety of sacubitril/valsartan in elderly hypertensive patients; and 2) Experimental groups had to include hypertensive patients aged $>55$ years taking sacubitril/ valsartan, whereas control groups had to include hypertensive patients aged $>55$ years treated with a comparator drug that could be an angiotensin-converting enzyme inhibitor (ACEi), an angiotensin receptor blocker (ARB), a calcium channel blocker (CCB) or a beta-blocker.

Animal experimental studies as well as case reports were eliminated from the meta-analysis. Similarly, all studies not written in English, duplicated studies, non-randomized studies, review articles, editorials, and expert opinions were excluded. Eligibility assessment and data extraction were carried out independently by two investigators (RDV and CA), with discrepancies resolved by thorough and in-depth discussion between them. Searched keywords were "sacubitril/valsartan", "angiotensin receptor-neprilysin inhibitor (ARNi)", "hypertension", and "RCT".

\section{Outcomes of interest}

Efficacy outcomes were the mean reductions in systolic blood pressure and diastolic blood pressure in the sitting position (msSBP and msDBP, respectively), as well as the mean reductions in ambulatory systolic blood pressure (maSBP) and ambulatory diastolic blood pressure (maDBP), calculated at the deadlines of 12 or 52 weeks. The safety outcome was any adverse event (AE) occurring during the follow-up. Studies were excluded if they did not report any of the above- mentioned outcomes.

\section{Statistical analysis}

Statistical analyses were performed using the software MIX (Meta-analysis with Interactive eXplanations), 2.0 Pro (BiostatXL, Englewood, NJ, USA) and RevMan 5.3 software (available from the Cochrane Collaboration; http//www. cochrane.org). Regarding the continuous variables, such as msSBP, msDBP, maSBP and maDBP, we adopted the weighted mean difference (WMD) using a fixed effects model. By contrast, for the outcome measures which were computed as binary variables, such as AEs, the effect size was represented as an odds ratio (OR) with a $95 \%$ confidence interval (CI) using a fixed effects model once again.

Heterogeneity was evaluated by Cochran's Q test, and calculation of the $\mathrm{I}^{2}$ statistic was assumed to represent the percentage of variability due to between-study variability. Publication bias was assessed using Begg's funnel plot. We performed sensitivity analyses to determine the impact of each study on the pooled results by removing the studies one at a time from the analysis and by assessing the changes in the pooled WMD (for msSBP, msDBP, maSBP and maDBP) and in the pooled OR (for AEs). Results were regarded as statistically significant if $\mathrm{P}$ was less than 0.05 .

\section{Results}

We were able to identify five randomized trials that met the required criteria [13-17]. Overall, 1,513 patients were randomized to receive either sacubitril/valsartan (at doses ranging from 100 to $400 \mathrm{mg}$ per day) or comparator drug olmesartan in three studies [15-17] and valsartan in two studies [13, 14] (Table 1). The duration of studies ranged from 4 to 52 weeks, with a mean duration (mean \pm standard deviation) of $95 \pm 82$ days $($ median $=70$ days $)$.

\section{Characteristics of included trials}

Some characteristics of the collected studies are summarized in Tables 1 and 2 [13-17]. The modalities of exclusion of unsuitable studies are outlined in Figure 1 (Quality of Reporting of Meta-analyses (QUOROM) flow diagram). The number of the patients randomized to receive sacubitril/valsartan was 760 , whereas that of the patients belonging to the control groups was 753 . The mean age of the patients in each trial was $\geq 55$ years.

\section{Adjunctive evaluations concerning risk of publication bias and stability of results}

Begg's funnel plot did not demonstrate any publication bias. Sensitivity analyses showed that no significant modifications were noticeable in the measures of effect size (pooled WMD 
Table 1. Main Features of Studies Incorporated in the Meta-Analysis

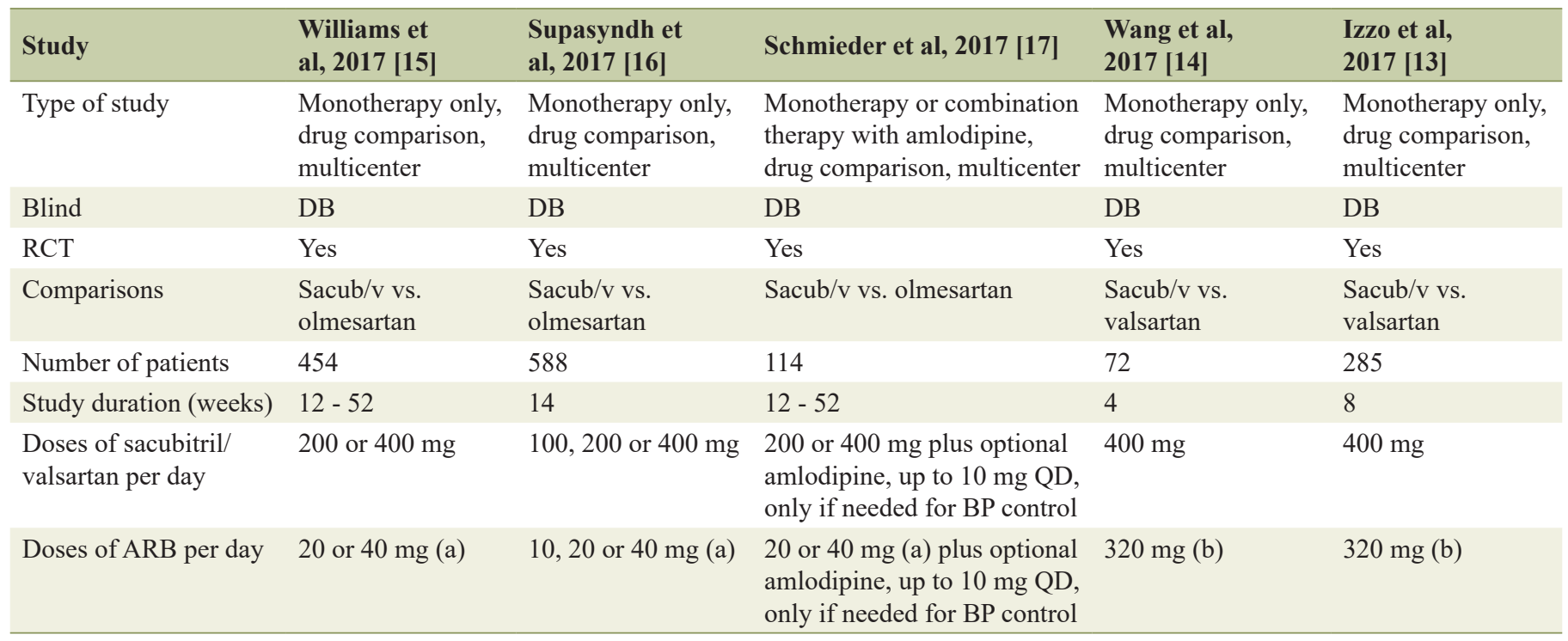

(a) Olmesartan was used as a comparator drug. (b) Valsartan was used as a comparator drug. DB: double blind; RCT: randomized controlled trial; ARB: angiotensin receptor blocker; QD: every day; BP: blood pressure.

and pooled OR) after excluding each study one by one.

\section{MsSBP and msDBP}

Both the msSBP and msDBP were calculated in all studies.

Both sitting systolic and sitting diastolic blood pressure levels showed a pronounced fall from baseline consequent to therapy with sacubitril/valsartan. The pooled WMD demonstrated that pressure reductions achieved with sacubitril/valsartan were more profound compared to those found after therapy with olmesartan or valsartan. Indeed, the comparison between sacubitril/valsartan and the comparator drugs (olmesartan in three studies and valsartan in two studies) demonstrated that for $\mathrm{msSBP}$ the pooled WMD was $-5.41 \mathrm{~mm} \mathrm{Hg}$ (95\% CI: -7.0 to $-3.83, \mathrm{P}<0.01$ ) (Fig. 2), while for $\mathrm{msDBP}$ the pooled WMD was $-1.22 \mathrm{~mm} \mathrm{Hg}(95 \% \mathrm{CI}:-2.15$ to -0.3 , P < 0.01) (Fig. 3), thereby evidencing a greater anti-hypertensive efficacy of sacubitril/valsartan with respect to ARBs (olmesartan or valsar$\tan$ ) in elderly hypertensive patients at 4-12 weeks.

Two RCTs $[15,17]$ considered the levels of msSBP and msDBP at 52 weeks achieved with sacubitril/valsartan and compared them with those obtained using olmesartan. Even in this case, when a comparison was made between the respective long-term anti-hypertensive effects of sacubitril/valsartan and olmesartan, the former was proven to be more efficacious than

Table 2. Several Anthropometric Measures Are Reported in the Table, Along With Baseline Blood Pressure Levels and Programmed Study Outcomes

\begin{tabular}{|c|c|c|c|c|c|}
\hline Study & $\begin{array}{l}\text { Williams et al, } \\
2017[15]\end{array}$ & $\begin{array}{l}\text { Supasyndh et } \\
\text { al, } 2017[16]\end{array}$ & $\begin{array}{l}\text { Schmieder et } \\
\text { al, } 2017 \text { [17] }\end{array}$ & Wang et al, 2017 [14] & $\begin{array}{l}\text { Izzo et al, } \\
2017[13]\end{array}$ \\
\hline $\begin{array}{l}\text { Age (years) (sacub val/ } \\
\text { controls, mean } \pm \mathrm{SD})\end{array}$ & $\begin{array}{l}68.2 \pm 5.73 / 67.2 \\
\pm 5.97\end{array}$ & $\begin{array}{l}70.5 \pm 4.67 / 70.9 \\
\pm 4.67\end{array}$ & $\begin{array}{l}60.5 \pm 7.8 / 59.2 \\
\pm 13.1\end{array}$ & $55.7 \pm 12.5 / 58.9 \pm 7.5$ & Mean 61 \\
\hline Men (sacub val/controls, \%) & $52 / 52.4$ & $48 / 52.1$ & $64.9 / 70.2$ & $64 / 64$ & NA \\
\hline $\begin{array}{l}\mathrm{BMI}(\text { sacub val/controls, } \\
\left.\mathrm{kg} / \mathrm{m}^{2}, \text { mean } \pm \mathrm{SD}\right)\end{array}$ & $27.4 \pm 4.5 / 28.1 \pm 4.9$ & $\begin{array}{l}23.4 \pm 4.15 / 23.6 \\
\pm 3.15\end{array}$ & $\begin{array}{l}29.1 \pm 5.6 / 29.6 \\
\pm 4.2\end{array}$ & $25.4 \pm 5.1 / 26.7 \pm 2.3$ & Mean 27.9 \\
\hline $\begin{array}{l}\text { Baseline DBP (sacub val/ } \\
\text { controls, mmHg, mean } \pm \mathrm{SD} \text { ) }\end{array}$ & $\begin{array}{l}85.8 \pm 8.62 / 85.8 \\
\pm 8.6\end{array}$ & $85.5 \pm 4.43 / 85.9 \pm 6.7$ & $86.7 \pm 7.5 / 87 \pm 5$ & $85.2 \pm 5.6 / 86.0 \pm 5.3$ & NA \\
\hline Outcomes & $\begin{array}{l}\text { msSBP, msDBP, } \\
\text { maSBP, maDBP, AEs }\end{array}$ & $\begin{array}{l}\text { msSBP, msDBP, } \\
\text { maSBP, maDBP, AEs }\end{array}$ & msSBP, msDBP & $\begin{array}{l}\text { msSBP, msDBP, } \\
\text { maSBP, maDBP, AEs }\end{array}$ & $\begin{array}{l}\text { msSBP, } \\
\text { msDBP, AEs }\end{array}$ \\
\hline
\end{tabular}

sacub val: sacubitril/valsartan; SD: standard deviation; BMI: body mass index; SBP: systolic blood pressure; DBP: diastolic blood pressure; AEs: adverse events; NA: not available; msSBP: mean reduction in sitting systolic blood pressure; msDBP: mean reduction in sitting diastolic blood pressure; maSBP: mean reduction in ambulatory systolic blood pressure; maDBP: mean reduction in ambulatory diastolic blood pressure. 


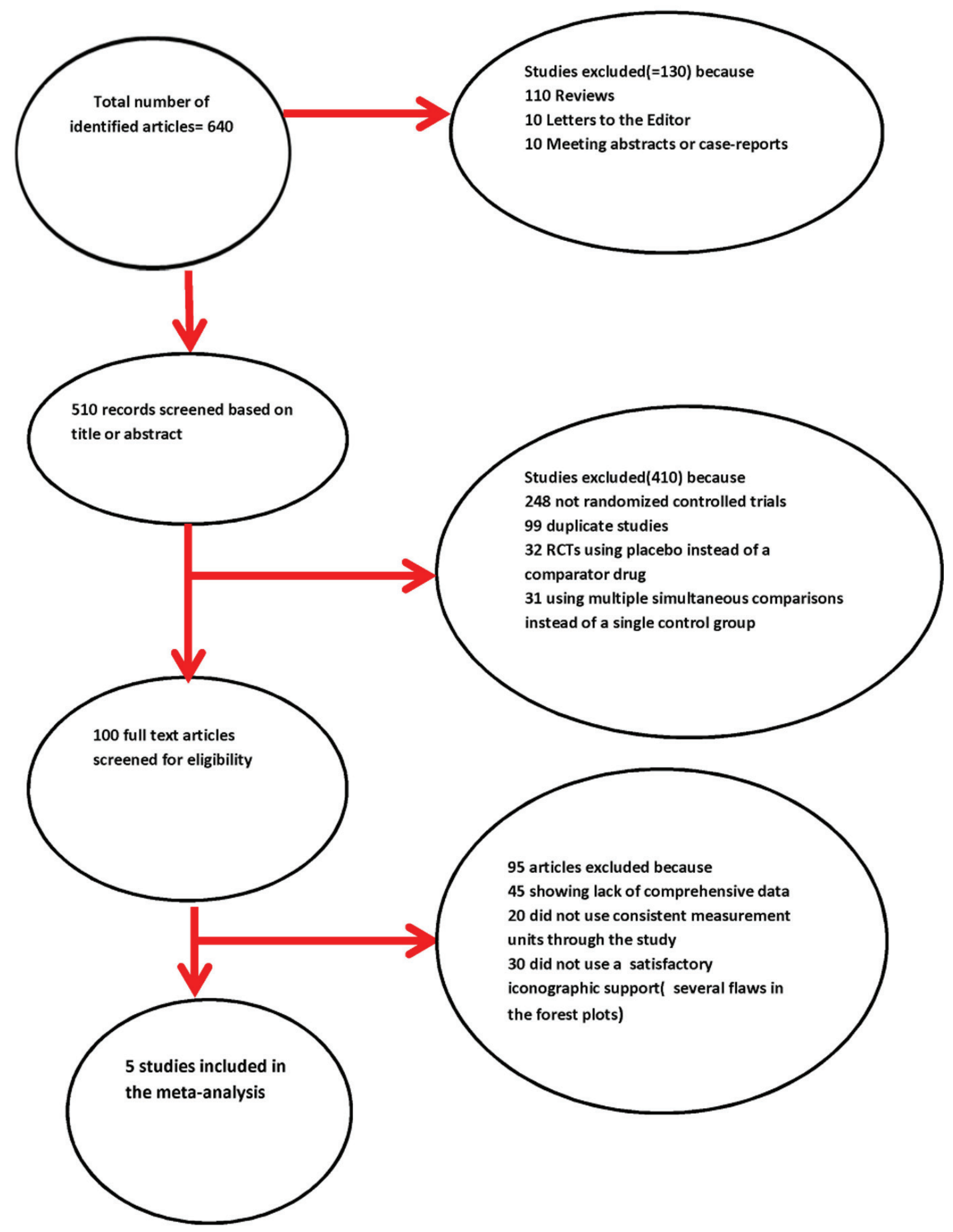

Figure 1. Quality of Reporting of Meta-analyses (QUOROM) statement's flow chart.

the latter. Indeed, for the msSBP value, the pooled WMD was $-2.77 \mathrm{~mm} \mathrm{Hg}(95 \% \mathrm{CI}:-5.16$ to $-0.39, \mathrm{P}=0.02)$ at 52 weeks (Fig. 4). Instead, for the msDBP value the pooled WMD at the same deadline was $-0.87 \mathrm{~mm} \mathrm{Hg}(95 \% \mathrm{CI}:-2.36$ to $0.63, \mathrm{P}=$ $0.26)$ (Fig. 4). This means that sacubitril/valsartan in the long term still reduced sitting systolic blood pressure more mark- 


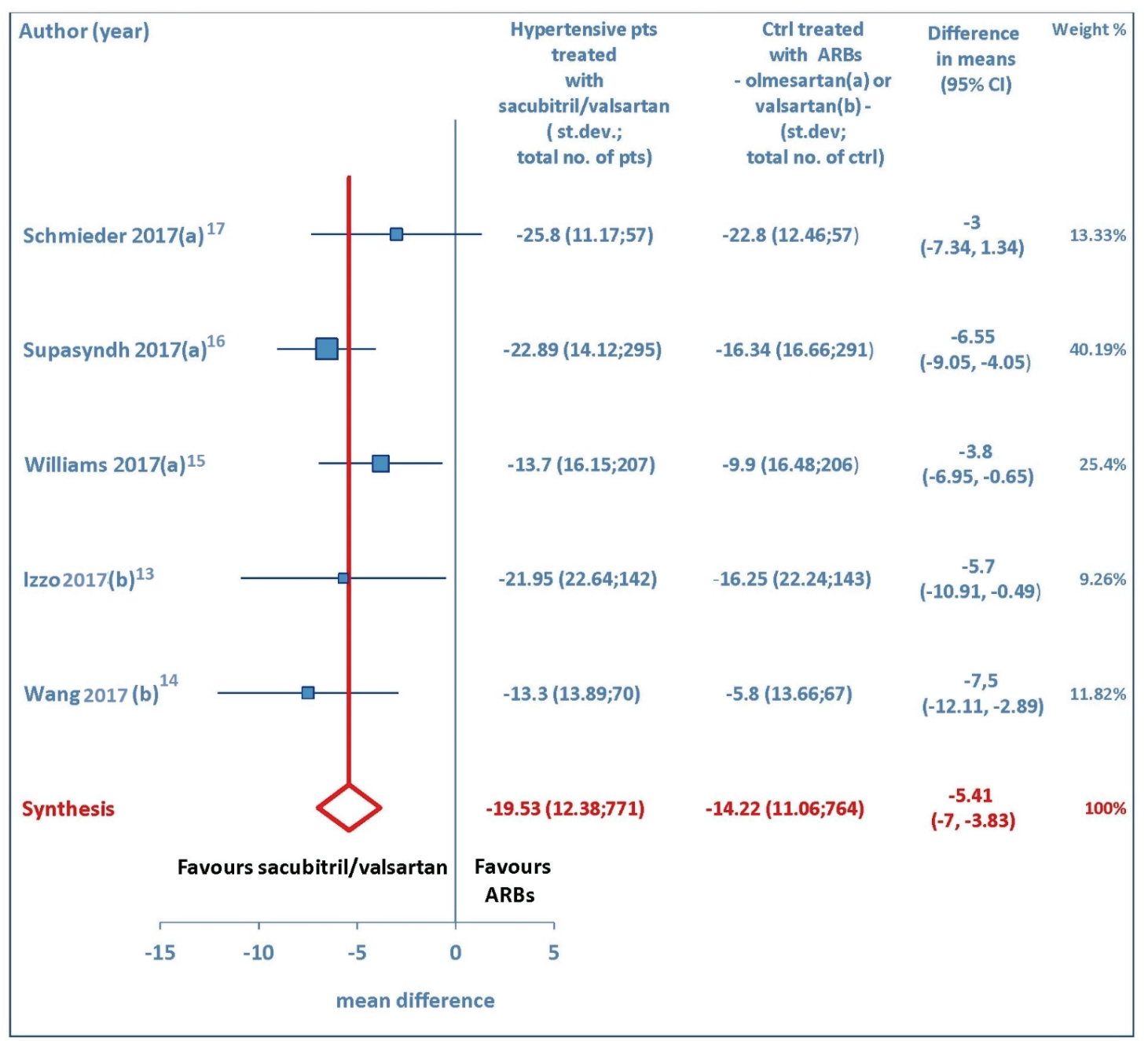

Figure 2. Mean reduction $(\mathrm{mm} \mathrm{Hg})$ in sitting systolic blood pressure (msSBP) in hypertensive patients treated with sacubitril/ valsartan compared to ARB-treated controls. (a) In the control group olmesartan was used as comparator drug. (b) In the control group valsartan was used as comparator drug. pts: patients; st.dev: standard deviation; ctrl: controls; ARBs: angiotensin receptor blockers; $\mathrm{Cl}$ : confidence interval.

edly compared to olmesartan. This also means that there was no significant difference between sacubitril/valsartan and olmesartan as regards msDBP at 52 weeks.

A total of three studies [14-16] explored the maSBP and maDBP from baseline. These trials showed that sacubitril/valsartan is more efficacious than olmesartan or valsartan in terms of reducing ambulatory systolic blood pressure (WMD $=-4.58$ $\mathrm{mm} \mathrm{Hg}, 95 \%$ CI: -5.62 to -3.54 ; $\mathrm{P}<0.01$ ) (Fig. 5) and ambulatory diastolic blood pressure (WMD $=-2.17 \mathrm{~mm} \mathrm{Hg}, 95 \%$ CI: -2.78 to $-1.56 ; \mathrm{P}<0.01$ ) (Fig. 6) in elderly hypertensive patients at 12 weeks.

\section{Effect of sacubitril/valsartan on AEs}

Several drug-related AEs were reported after therapy with sacubitril/valsartan or ARB in four studies [13-16]. The pooled data showed that AEs were more numerous in sacubitril/val- sartan group than olmesartan or valsartan groups $(\mathrm{OR}=1.27$, 95\% CI: 1.03 to $1.57 ; \mathrm{P}=0.03$ ) (Fig. 7). More exactly, the incidence of AEs was $37.6 \%$ in the patients treated with sacubitril/valsartan and $28.7 \%$ in the patients taking an ARB, with the abovementioned values indicating the overall percentage estimates, calculated by averaging the percentage frequencies of AEs detected in each of the four studies which reported AEs [13-16]. The commonly reported AEs were nasopharyngitis, hyperuricemia, upper respiratory tract infection, and dizziness.

\section{Discussion}

A synthetic representation of comparison between sacubitril/ valsartan and ARBs, either olmesartan or valsartan, should firstly highlight that sacubitril/valsartan had a greater efficacy in reducing sitting systolic blood pressure, sitting dias- 


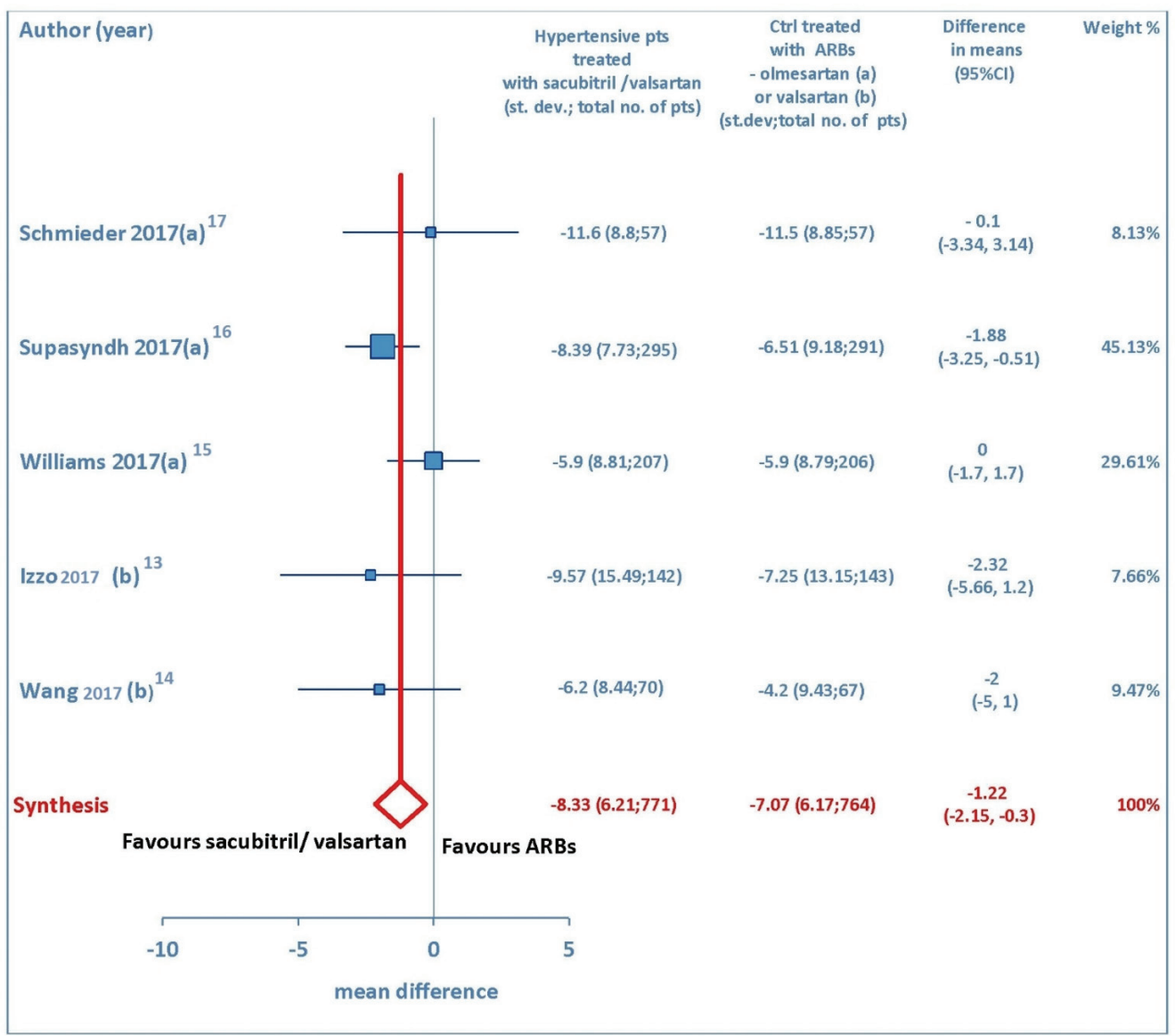

Figure 3. Mean reduction ( $\mathrm{mm} \mathrm{Hg}$ ) in sitting diastolic blood pressure (msDBP) in hypertensive patients treated with sacubitril/ valsartan compared to ARB-treated controls. (a) In the control group olmesartan was used as comparator. (b) In the control group valsartan was used as comparator. pts: patients; st.dev: standard deviation; ctrl: controls; ARBs: angiotensin receptor blockers; $\mathrm{Cl}$ : confidence interval.

tolic blood pressure, ambulatory systolic blood pressure and ambulatory diastolic blood pressure $(\mathrm{P}<0.05$ for each of the four outcomes) at the established endpoints of 4-12 weeks.
Moreover, a more profound reduction in sitting systolic blood pressure in sacubitril/valsartan group compared to olmesartan group $(\mathrm{P}=0.02)$ has been proved to be kept for up to 52 weeks.

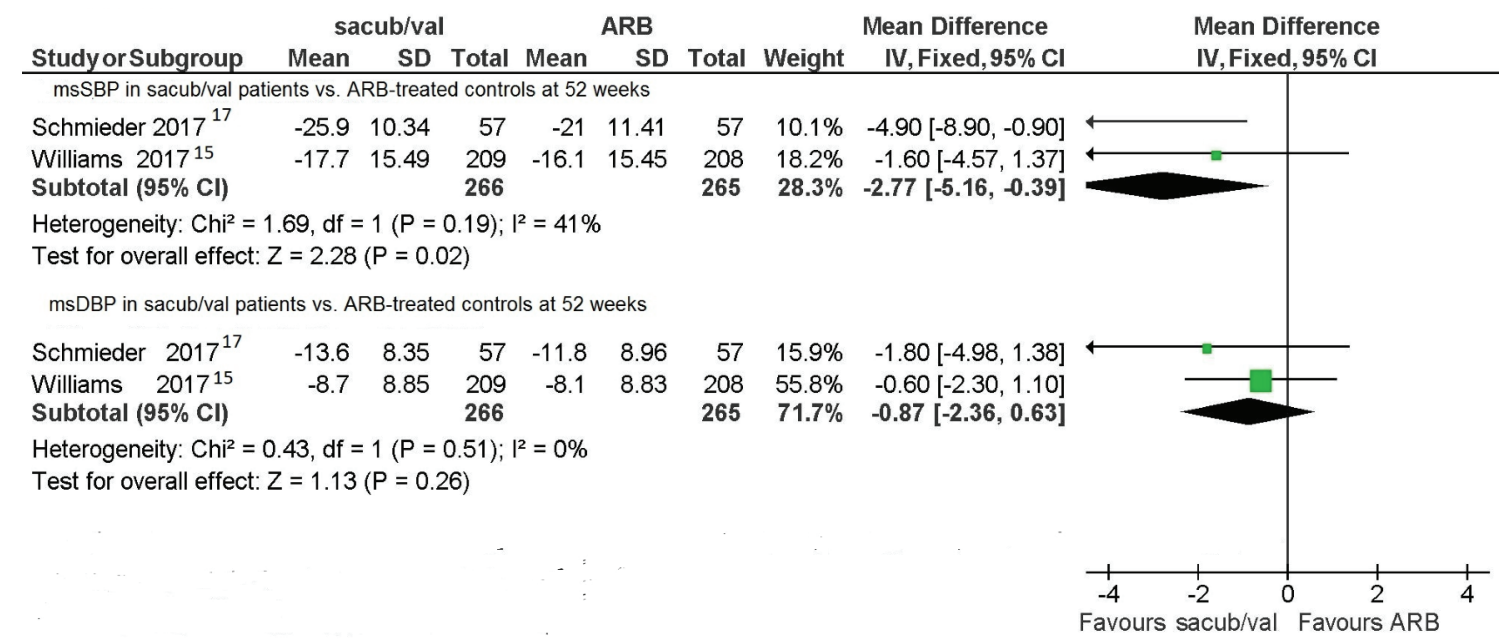

Figure 4. Mean sitting blood pressures (msSBP and msDBP) in sacubitril/valsartan-treated patients vs. ARB-treated controls. 


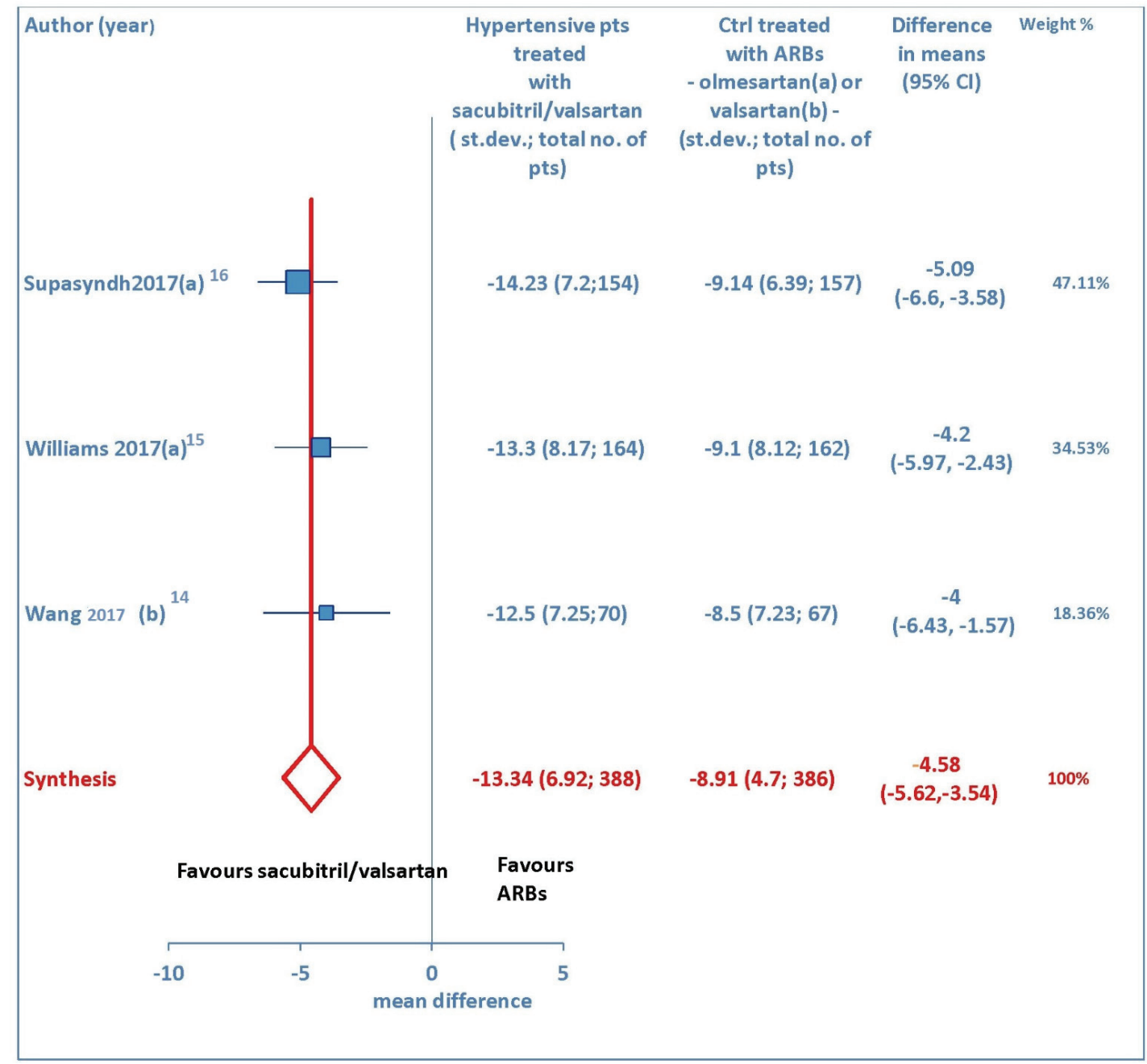

Figure 5. Mean reduction $(\mathrm{mm} \mathrm{Hg})$ in ambulatory systolic blood pressure (maSBP) in hypertensive patients treated with sacubitril/valsartan compared to ARB-treated controls. (a) In the control group olmesartan was used as comparator. (b) In the control group valsartan was used as comparator. pts: patients; st.dev: standard deviation; ctrl: controls; ARBs: angiotensin receptor blockers; Cl: confidence interval.

The sacubitril/valsartan conjugation molecule undoubtedly possesses innovative modalities of cardioprotective action. Sacubitril, a neprilysin inhibitor, taken alone would have a neutral effect on blood pressure because it induces not only an increase in the half-life of cardiac natriuretic peptides (atrial natriuretic factor (ANF) and brain natriuretic peptide (BNP)) but also a concomitant slowing down of degradation of peptides with a vasoconstrictor effect, such as angiotensin II and the endothelins [7].

Thus, it was necessary to realize a conjugation molecule that would combine the sacubitril to an angiotensin receptor blocker, namely the valsartan. Therefore, sacubitril/valsartan is the first case of a drug with a dual inhibitory effect consisting of the combined inhibition of angiotensin II receptors and of neutral endopeptidase which degrades natriuretic peptides. The attribute of "parent drug" of a new class of cardioprotective agents, the ARNis has therefore been conferred to the sacubitril/valsartan [4].
Sacubitril/valsartan reduces the hemodynamic loading of the ventricles and the left ventricular end-diastolic pressure through the enhancement of the endogenous B-type natriuretic peptide (BNP), which is secreted by the ventricular myocardium in response to increases in ventricular preload leading to cardiomyocyte stretching. The action of the BNP, which entails a reduction in the left ventricle's wall stress, is supported and amplified by the sacubitril, which prevents its degradation by neprilysin $[6,7]$. The innovative mechanism of action of sacubitril/valsartan and its favorable effects, in particular, the demonstrated prolongation of the life expectancy for patients with heart failure with reduced left ventricular ejection fraction (HFrEF) [10], have once again drawn attention to a great therapeutic potential possessed by the cardiac hormone system (ANF and BNP).

The heart is an organ that produces hormonal substances for the preservation of cardiocirculatory homeostasis [19], but the importance of this feature has not been fully considered 


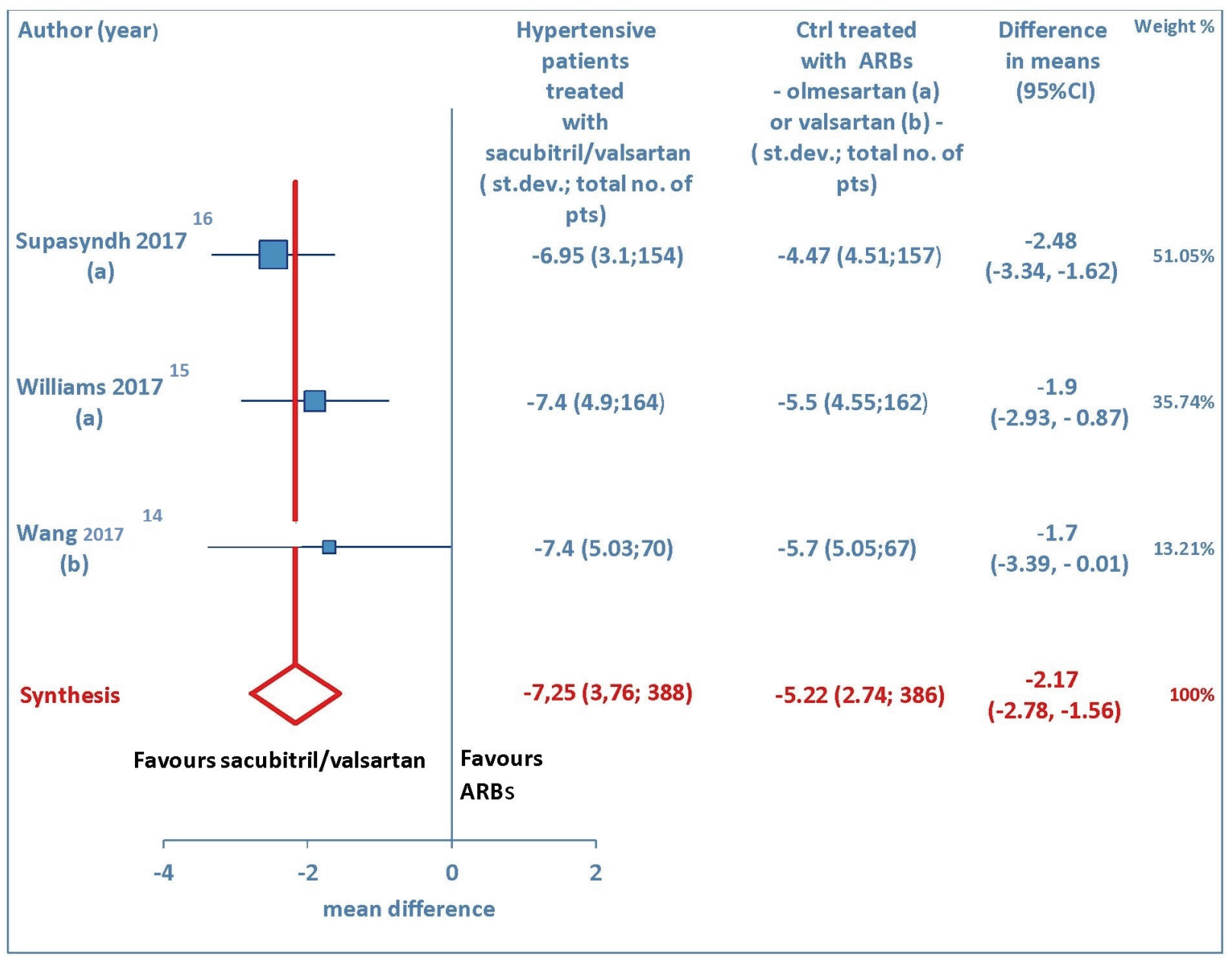

Figure 6. Mean reduction $(\mathrm{mm} \mathrm{Hg})$ in ambulatory diastolic blood pressure (maDBP) in hypertensive patients treated with sacubitril/valsartan compared to ARB-treated controls. (a) In the control group olmesartan was used as comparator. (b) In the control group valsartan was used as comparator. pts: patients; st.dev: standard deviation; ctrl: controls; ARBs: angiotensin receptor blockers; Cl: confidence interval.

until now. However, now the BNP has been shown, thanks to the advent of sacubitril/valsartan that inhibits its degradation, to be a powerful cardioprotective agent, which contains in itself natriuretic, diuretic, vasodilating, anti-adrenergic and antiapoptotic properties [20, 21].

In our meta-analysis we explored the vasodilating and anti-hypertensive properties of sacubitril/valsartan, based on the comparison with two comparator drugs, belonging to the ARB class (olmesartan and valsartan). The endpoints of interest were msSBP, msDBP, maSBP and maDBP. For systolic blood pressure, in each of the five examined trials, sacubitril/valsartan demonstrated a significantly stronger anti-hypertensive effect than ARBs, both for sitting pressure and for ambulatory pressure. In addition, the anti-hypertensive effect, for systolic but not for diastolic pressure, was more intense compared to that of ARBs in detections at 52 weeks. Furthermore, with the evaluation of pooled data through the construction of forest plots, the pooled WMD was always indicative of a significant therapeutic advantage with the use of sacubitril/valsartan compared to ARBs.
In conclusion, it can be said that the sacubitril/valsartan has all the credentials to be introduced in the armamentarium of anti-hypertensive drugs for elderly patients. In fact, it exerts an incisive action in predominantly systolic or isolated systolic hypertension, typical of advanced age. In the measurements taken at 52 weeks the mean reduction in blood pressure levels persists unchanged compared to values found at 12 weeks, and it has proved to be more pronounced compared to olmesartan, with regard to systolic pressure, whereas the measurements at the same deadline do not document any significant difference in the diastolic pressure's decline compared to olmesartan.

\section{Conclusions}

Our meta-analysis, although limited to only five studies for a total of 1,513 patients, shows that sacubitril/valsartan, at doses of 100 - $400 \mathrm{mg}$ once daily, is effective in reducing high blood pressure values in elderly hypertensive patients, with an ac- 


\begin{tabular}{|c|c|c|c|c|c|}
\hline Author (year) & & $\begin{array}{c}\text { Pts treated } \\
\text { with } \\
\text { sacubitril/valsartan } \\
\text { who } \\
\text { experienced AEs } \\
\text { (total no. of pts) }\end{array}$ & $\begin{array}{c}\text { Ctrl treated } \\
\text { with ARBs } \\
\text { - olmesartan (a) } \\
\text { or valsartan ( b) - } \\
\text { who experienced AEs } \\
\text { ( total no. of ctrl) }\end{array}$ & $\begin{array}{l}\text { Odds ratio } \\
(95 \% \mathrm{Cl})\end{array}$ & Weight \% \\
\hline Supasyndh $2017\left(\right.$ a) ${ }^{16}$ & — & 141 (296) & $113(292)$ & $\begin{array}{c}1.44 \\
(1.04,2)\end{array}$ & $39.17 \%$ \\
\hline Williams 2017(a) & - & 132 (229) & 121 (225) & $\begin{array}{c}1.17 \\
(0.81,1.69)\end{array}$ & $34 \%$ \\
\hline $\mid 2202017$ (b) & & 43 (142) & 37 (143) & $\begin{array}{c}1.24 \\
(0.74,2.09)\end{array}$ & $16.9 \%$ \\
\hline Wang2017 (b) & & $23(70)$ & $22(67)$ & $\begin{array}{c}1 \\
(0.49,2.04)\end{array}$ & $9.93 \%$ \\
\hline Synthesis & & 339 (737) & $293(727)$ & $\begin{array}{c}1.27 \\
(1.03,1.57)\end{array}$ & $100 \%$ \\
\hline $\begin{array}{l}\text { AEs are less frequent in } \\
\text { sacubitril/valsartan group }\end{array}$ & $\begin{array}{l}\text { AEs are } \\
\text { in ARB } \varepsilon\end{array}$ & $\begin{array}{l}\text { less frequent } \\
\text { group }\end{array}$ & & & \\
\hline 0,25 & 1 odds ratio & 4 & & & \\
\hline
\end{tabular}

Figure 7. Adverse events (AEs) in sacubitril/valsartan-treated patients vs. ARB-treated controls. (a) In the control group olmesartan was used as comparator. (b) In the control group valsartan was used as comparator. pts: patients; ctrl: controls; ARBs: angiotensin receptor blockers; Cl: confidence interval.

ceptable incidence of side effects. Comparison with ARBs consistently showed superiority of the anti-hypertensive effect of sacubitril/valsartan. Therefore, based on preliminary evidence from these small trials, sacubitril/valsartan could be proposed as an elective drug for predominantly systolic or isolated systolic hypertension in elderly patients. However, further RCTs with larger sample sizes would be appropriate in order to corroborate the favorable results of our meta-analysis, and definitively validate the use of sacubitril/valsartan as an anti-hypertensive drug, especially suitable for elderly hypertensive patients.

\section{Conflict of Interest}

The authors declare that they have no conflict of interest concerning the present article.

\section{Financial Support}

The authors declare that the present article has not benefitted from any source of funding.

\section{References}

1. Kario K, Sun N, Chiang FT, Supasyndh O, Baek SH, Inubushi-Molessa A, Zhang $\mathrm{Y}$, et al. Efficacy and safety of LCZ696, a first-in-class angiotensin receptor neprilysin inhibitor, in Asian patients with hypertension: a randomized, double-blind, placebo-controlled study. Hypertension. 2014;63(4):698-705.

2. Ito S, Satoh M, Tamaki Y, Gotou H, Charney A, Okino N, Akahori M, et al. Safety and efficacy of LCZ696, a first-in-class angiotensin receptor neprilysin inhibitor, in Japanese patients with hypertension and renal dysfunction. Hypertens Res. 2015;38(4):269-275.

3. Kario K, Tamaki Y, Okino N, Gotou H, Zhu M, Zhang J. LCZ696, a first-in-class angiotensin receptor-neprilysin inhibitor: the first clinical experience in patients with severe hypertension. J Clin Hypertens (Greenwich). 2016;18(4):308-314.

4. Andersen MB, Simonsen U, Wehland M, Pietsch J, Grimm D. LCZ696 (Valsartan/Sacubitril) - A possible new treatment for hypertension and heart failure. Basic Clin Pharmacol Toxicol. 2016;118(1):14-22.

5. Ruiz-Hurtado G, Ruilope LM. Advantages of sacubitril/ 
valsartan beyond blood pressure control in arterial hypertension. Eur Heart J. 2017;38(44):3318-3320.

6. Campbell DJ. Long-term neprilysin inhibition - implications for ARNIs. Nat Rev Cardiol. 2017;14(3):171-186.

7. Riddell E, Vader JM. Potential expanded indications for neprilysin inhibitors. Curr Heart Fail Rep. 2017;14(2):134-145.

8. Moncloa F, Sromovsky JA, Walker JF, Davies RO. Enalapril in hypertension and congestive heart failure. Overall review of efficacy and safety. Drugs. 1985;30(Suppl 1):82-89.

9. Todd PA, Heel RC. Enalapril. A review of its pharmacodynamic and pharmacokinetic properties, and therapeutic use in hypertension and congestive heart failure. Drugs. 1986;31(3):198-248.

10. McMurray JJ, Packer M, Desai AS, Gong J, Lefkowitz MP, Rizkala AR, Rouleau JL, et al. Angiotensin-neprilysin inhibition versus enalapril in heart failure. N Engl J Med. 2014;371(11):993-1004.

11. De Vecchis R, Ariano C, Di Biase G, Noutsias M. Sacubitril/valsartan for heart failure with reduced left ventricular ejection fraction : A retrospective cohort study. Herz. 2018.

12. De Vecchis R, Ariano C, Di Biase G, Noutsias M. Cognitive performance of patients with chronic heart failure on sacubitril/valsartan : A retrospective cohort study. Herz. 2018 .

13. Izzo JL, Jr., Zappe DH, Jia Y, Hafeez K, Zhang J. Efficacy and safety of crystalline valsartan/sacubitril (LCZ696) compared with placebo and combinations of free valsartan and sacubitril in patients with systolic hypertension: the RATIO study. J Cardiovasc Pharmacol. 2017;69(6):374381.
14. Wang TD, Tan RS, Lee HY, Ihm SH, Rhee MY, Tomlinson B, Pal P, et al. Effects of sacubitril/valsartan (LCZ696) on natriuresis, diuresis, blood pressures, and NT-proBNP in salt-sensitive hypertension. Hypertension. 2017;69(1):32-41.

15. Williams B, Cockcroft JR, Kario K, Zappe DH, Brunel PC, Wang Q, Guo W. Effects of sacubitril/valsartan versus olmesartan on central hemodynamics in the elderly with systolic hypertension: the PARAMETER study. Hypertension. 2017;69(3):411-420.

16. Supasyndh O, Wang J, Hafeez K, Zhang Y, Zhang J, Rakugi H. Efficacy and safety of sacubitril/valsartan (LCZ696) compared with olmesartan in elderly Asian patients $(>/=65$ Years) with systolic hypertension. Am J Hypertens. 2017;30(12):1163-1169.

17. Schmieder RE, Wagner F, Mayr M, Delles C, Ott C, Keicher C, Hrabak-Paar M, et al. The effect of sacubitril/valsartan compared to olmesartan on cardiovascular remodelling in subjects with essential hypertension: the results of a randomized, double-blind, active-controlled study. Eur Heart J. 2017;38(44):3308-3317.

18. Moher D, Liberati A, Tetzlaff J, Altman DG, the PRISMA Group. Preferred reporting items for systematic reviews and meta-analyses: the PRISMA statement. BMJ. 2009;339:b2535.

19. Ogawa T, de Bold AJ. The heart as an endocrine organ. Endocr Connect. 2014;3(2):R31-44.

20. de Bold AJ. Thirty years of research on atrial natriuretic factor: historical background and emerging concepts. Can J Physiol Pharmacol. 2011;89(8):527-531.

21. Volpe M, Rubattu S, Burnett J, Jr. Natriuretic peptides in cardiovascular diseases: current use and perspectives. Eur Heart J. 2014;35(7):419-425. 